\title{
ANOREXIA Y USO DE REDES SOCIALES EN ADOLESCENTES
}

\section{Anorexia and use of social networks in adolescents}

Florencia Lucciarini*, Analía Verónica Losada**, Ramiro Moscardi*** Pontifica Universidad Católica Argentina, Argentina

\begin{abstract}
Resumen
El propósito de este artículo teórico consistió en analizar la posible relación entre el uso de redes sociales y el desarrollo de la anorexia en adolescentes de 10 a 19 años mediante un enfoque sistémico y cognitivo conductual. Se describió el concepto de Anorexia Nerviosa (AN), la cual se incluye dentro de los trastornos de la conducta alimentaria (TCA) y se estudiaron las redes sociales más empleadas por esta franja etaria. Se concluye sobre la relación significativa entre el desarrollo de AN y el uso de redes sociales. Los cambios corporales en el adolescente, así como la necesidad de validación de su identidad por parte de su entorno, lo sitúan en una situación de vulnerabilidad. Si bien las redes sociales pueden ser un factor para esa validación positiva, podrían constituir un factor de riesgo desencadenante de un TCA, particularmente la $A N$, en adolescentes.
\end{abstract}

Palabras clave: trastornos de la conducta alimentaria, anorexia, redes sociales, adolescencia, consecuencias psicológicas.

\begin{abstract}
The aim of this theoretical article was analyze the possible relationship between the use of social networks and the development of anorexia in adolescents from 10 to 19 years old through a systemic and cognitive-behavioral approach. The concept of Anorexia Nervosa (AN), which is included within the eating disorders (ED), was described and the social networks most used by this age range were studied. It is concluded about the significant relationship between the development of $A N$, and the use of social networks. The body changes in adolescents, as the need for approval of their identity by their environment, place them in a situation of vulnerability. Although the social networks can be a factor for a positive validation, they could constitute a risk factor that triggers an ED, particularly $A N$, in adolescents.
\end{abstract}

Keywords: eating disorders, anorexia, social networks, adolescence, psychological consequences.

\footnotetext{
* Psicóloga. florencialucciarini@gmail.com. https://orcid.org/0000-0001-8016-7801

** Psicóloga. analia_losada@yahoo.com.ar. https://orcid.org/0000-0003-0488-4651

*** Psicólogo. ramimoscardi@gmail.com. https://orcid.org/0000-0002-1932-5249
}

Cualquier uso que se haga de este artículo debe incluir: Autor / Título original de la publicación / ISSN 


\section{INTRODUCCIÓN}

El uso de redes sociales puede ser considerado un factor de riesgo desencadenante de Anorexia Nerviosa (AN), específicamente en adolescentes que se encuentran en una etapa vulnerable debido al proceso de confirmación y conformación de su identidad. La presente investigación busca analizar la posible relación entre el uso de redes sociales y la anorexia nerviosa en adolescentes de 10 a 19 años, con exclusión sobre anorexia comórbida a otros trastornos psicopatológicos.

La última década ha sido atravesada por una irrupción en incremento de redes sociales, principalmente utilizadas por un público adolescente y joven que con frecuencia se nutren de las imágenes publicadas que comparan con sus cuerpos. Este predominio visual mediado por el ideal de un cuerpo perfecto podría operar a favor de la insatisfacción corporal impulsando a la delgadez.

La posible asociación entre comportamientos en redes sociales relacionados con la apariencia física y un trastorno de la conducta alimentaria son fenómenos de relevancia actual cuando los jóvenes sostienen el uso de aplicaciones digitales como medios comunicacionales preponderantes.

\section{ADOLESCENCIA}

La adolescencia es una etapa caracterizada por un ritmo acelerado de crecimiento y de cambios, con la maduración física y sexual que preparan al adolescente para la etapa adulta, que abarca aproximadamente entre los 10 a 19 años.

En ella se producen experiencias que construyen el camino de la identidad, la progresiva autonomía social y económica y la adquisición de las aptitudes necesarias para establecer relaciones y asumir funciones adultas, junto con una capacidad de razonamiento abstracto (Organización Mundial de la Salud, 2020).

La población con riesgo a desarrollar un TCA corresponde a un $80 \%$ de adolescentes, mayoritariamente mujeres, siendo la proporción de, un hombre por cada diez mujeres quienes relatan insatisfacción con su peso y aspecto corporal, por lo cual se someten a dietas u otras maneras de controlar el aumento de peso. Es un trastorno que mayormente se encuentra presente en la etapa de la adolescencia, etapa caracterizada por una transición, donde se generan cambios físicos, sociales, psicológicos y cognitivos siendo los adolescentes particularmente vulnerables o influenciables por los comentarios que escuchan o reciben (Véliz et al., 2019).

En los hombres, el ideal de belleza sufrió modificaciones a lo largo del tiempo, actualmente el cuerpo ideal para la mayoría de los hombres es un cuerpo musculoso, con abdominales bien definidos, siendo la musculatura y la grasa corporal las principales preocupaciones que podrían causar insatisfacción corporal, por lo cual muchos de ellos acceden a dieta rica en proteínas y baja en grasas, excesivo ejercicio, sustancias que mejoren su rendimiento y el uso de suplementos quemadores de grasa (Dakanalis, et al., 2017).

\section{ANOREXIA NERVIOSA}

La palabra anorexia contiene su origen en el vocabulario griego anorektous y se la transcribe como falta de apetito. Etimológicamente se encuentra conformada por el prefijo an que implica negación y orexis que se entiende como apetito, por lo cual, se lo traduce como sin apetito o pérdida de apetito. Con relación al adjetivo nerviosa conduce a su origen psicológico (Fragale, 2010).

La AN se caracteriza por la restricción de la ingesta en relación con las necesidades, que conduce a un peso corporal significativamente bajo con la relación al sexo, edad, salud física y el curso del desarrollo. También genera miedo a engordar o ganar peso y una alteración en la forma en que una persona percibe su propio peso. Las personas con anorexia nerviosa se pueden clasificar en dos grupos, por un lado anorexia purgativa, caracterizada por la conducta de atracones, seguida de purgas, y por el otro, la anorexia restrictiva, con dieta, ayuno y/o ejercicio excesivo. La pérdida de peso y el miedo, junto con el rechazo a mantener el peso corporal del mínimo normal para su talla y edad, es una de sus características principales (American Psychiatric Association, 2014). En los TCA el núcleo psicopatológico se basa en una extrema valoración 
tanto de la imagen física, como del control del peso corporal, desencadenando conductas tales como la reducción de la ingesta o el sometimiento a dietas peligrosas (Celis y Roca, 2011).

Los trastornos de la conducta alimentaria han aumentado notablemente en los últimos años, convirtiéndose en una enfermedad crónica muy frecuente ya que se someten a riesgos extremos para lograr conseguir el ideal que ellos consideran sinónimo de belleza (Marengo et al., 2018). Los TCA en el 90\% de los casos afecta a las mujeres adolescentes (Losada y Whittingslow, 2013), constituyendo una enfermedad crónica frecuente en la población femenina por su creciente incidencia en las últimas tres décadas y por la gravedad de la patología, así como también por la resistencia al tratamiento (Serra, 2015).

Los factores que pueden aumentar el riesgo de su aparición pueden ser biológicos tales como obesidad o sobrepeso y la genética o la pubertad; psicológicos como la preocupación por el peso por internalización del ideal de delgadez; la insatisfacción con la imagen corporal y baja autoestima; socioculturales que hacen referencia a la presión social sobre el peso, la influencia de los medios de comunicación y la influencia de las relaciones interpersonales (Portela de Santana et al., 2012).

Respecto a los elementos culturales, generalmente hay una tendencia social instaurada donde se cree que la extrema delgadez es sinónimo de belleza, esto genera que muchas personas se sometan a dietas extremas o a consumir productos que ayuden a adelgazar para poder cumplir con el objetivo del estándar de belleza de la sociedad. También hay que considerar que existen factores familiares que pueden influir en el desarrollo de un trastorno alimentario, tales como antecedentes familiares de obesidad, pobre comunicación con la familia y especialmente con la madre, dificultad en la alimentación o crianza sobreprotectora (Losada y Whittingslow, 2013).

Si bien los TCA pueden desarrollarse en cualquier persona, su aparición es más frecuente en el sexo femenino, como así también en los finales de la adolescencia y comienzos de la juventud ya que en este rango de edad se producen los mayores cambios corporales, lo cual podría desencadenar sentimientos de insatisfacción corporal. Además del sexo femenino, las personas que presentan marcados ideales estéticos sociales, junto a altos niveles de exigencia, como bailarines, modelos, deportistas, pertenecen a un grupo de riesgo de los cuales podrían desarrollar TCA ya que deben cumplir con un físico socialmente aceptado, el cual representa a la delgadez o la musculatura, según se trate de mujeres o de hombres (Meler y Planell, 2013)

Lo que caracteriza a los pacientes con anorexia es una búsqueda de la delgadez que conlleva a restringir la ingesta, acompañado de una alteración de la imagen corporal (Losada y Marmo, 2013), perfeccionismo y autoexigencia en cada actividad que realizan (Losada y Whittingslow, 2013).

El trastorno se manifiesta a varios niveles: a nivel conductual con el esfuerzo por mantener el peso corporal mínimo según su edad; a nivel psicológico ya que incluye alteraciones en la percepción del peso, autovaloraciones negativas, pensamientos obsesivos, desequilibrio emocional (Caballo y Simón, 2013), y a nivel fisiológico se presentan alteraciones como la amenorrea, es decir, la ausencia de al menos tres ciclos menstruales seguidos (Losada y Whittingslow, 2013).

En la anorexia nerviosa se presentan factores de riesgos psicológicos como la preocupación por el peso y la internalización del ideal de delgadez, ya que el no lograr el peso querido genera insatisfacción y conductas de riesgo. Para lograr esta disminución de peso se someten a dietas extremas, uso de laxantes, ayuno, vómitos ya que piensan que esto traerá beneficios físicos y psicológicos, aunque no es así. Además, la imagen corporal está atravesada por influencias socioculturales, lo cual puede desencadenar baja autoestima y afecto negativo (Arnau, 2016). Es decir, la AN suele comenzar con una dieta o control de peso, como resultado de presiones socioculturales y el consumo de redes sociales o medios de comunicación los cuales han sido identificados como un factor de riesgo especialmente en adolescentes mujeres ya que internalizan una figura ideal de bajo peso corporal, y se someten a riesgos extremos para llegar a alcanzar esa creencia de perfección, en cuanto que los hombres idealizan la musculatura como sinónimo de belleza, 
por lo cual realizan actividad física en exceso, la cual va más allá de sus límites físicos (Rodgers et. al. 2019).

Además, las personas con TCA sufren alteraciones psicológicas cognitivas, conductuales y emocionales. En cuanto a las distorsiones psicológicas cognitivas, se destacan las abstracciones selectivas las cuales son aquellas en las que se presta atención solo al aspecto negativo de la situación sin tener en cuenta el resto del contexto, por lo cual, en el caso de una persona que sufre AN pensará que, por ejemplo, por comer una sola galletita, no podrá controlarse y comerá más de las que se permite. Pueden presentarse magnificaciones de consecuencias negativas, en las cuales se exagera lo negativo de una situación; en el caso de una persona con AN, si pesara menos antes de ingerir un alimento, y luego aumentara un poco de peso, la persona creerá que no podrá volver a ingerir ese alimento normalmente ya que le generaría un aumento de peso. Generalmente suele estar presente el pensamiento dicotómico en el cual hay un extremo de todo o nada, por lo que una paciente con AN podría pensar que por tener un atracón, deberá hacer un ayuno de mínimo dos días para compensarlo. También podrían aparecer ideas autorreferenciales en las cuales la persona cree que en el momento que esté comiendo, todos las personas presentes la estarán mirando, como así también pueden presentarse inferencias arbitrarias las cuales son producidas cuando se sacan conclusiones de una situación aunque no sean ciertas o estén apoyadas por los hechos, por ejemplo, una persona con $\mathrm{AN}$ puede pensar que comiendo lo que le gusta, la hará engordar y no querrá volver a consumir ese alimento (Escursell, 2017).

Para el modelo cognitivo, los sentimientos y conductas de las personas están determinados por la forma en que una persona percibe y les da significado a sus experiencias, por lo cual, tener en cuenta la cognición resulta fundamental en el mantenimiento o desencadenamiento de la AN ya que la autoevaluación negativa genera conductas que no son apropiadas (Losada y Donovan, 2017). La mayoría de las personas que sufren anorexia nerviosa y presentan un cuerpo delgado, afirman que no perciben a su cuerpo de esa manera (Escursell, 2017).

Respecto a las alteraciones emocionales pueden aparecer sentimientos depresivos y manifestaciones como la presencia de tristeza, insomnio, irritabilidad, como así también ansiedad, junto a una insatisfacción corporal y sentimientos de culpa si la persona ha ingerido algún alimento (Escursell, 2017). Además, puede presentarse retraimiento social, ideas obsesivas, actitud omnipotente y la posible presencia de ideación suicida inclusive (Hernández et al., 2020).

Anteriormente el internamiento hospitalario en este tipo de pacientes consistía en un tratamiento largo que se extendía hasta que el sujeto era estabilizado totalmente, siguiendo con tratamiento psiquiátrico, aunque esto implicara un alto costo económico. Actualmente se hospitaliza a los pacientes cuando su vida corra riesgo inminente, donde se intentará estabilizar los signos vitales y se determina que no haya otra enfermedad que explique el cuadro del paciente, luego se tratará el trastorno metabólico que provocó el internamiento, como así también se tendrá en cuenta el riesgo por lesiones auto provocadas. La necesidad de internamiento médico será evaluada por un equipo de profesionales conformado por un médico, psicólogo, nutricionista y psiquiatra, aunque en la mayoría de los casos la recuperación suele ser primero médica y luego psicológica, por ello es importante realizar un seguimiento psicológico luego de la internación (Castro y Araya, 2020).

En los años setenta, se consideraba a los trastornos alimentarios como una enfermedad psicosomática y no siempre se tenía en cuenta a la familia del paciente para el tratamiento (Losada y Whittingslow, 2013). Luego, esta manera de abordar el trastorno cambió con la aparición de la terapia sistémica ya que para ella los síntomas forman parte de las interacciones que se generan dentro de un sistema familiar, por lo cual este enfoque permite que se vincule el síntoma con el entorno, es decir, no solo se centra en el paciente, sino que también incluye a su familia para participar en la resolución del conflicto. La familia podría influir en el desarrollo de un TCA por lo cual resulta fundamental incorporarlos en el tratamiento sistémico que apuntará a eliminar el síntoma anoréxico principalmente, pero luego se centrará en lograr cambios en las pautas familiares para mejorar su organización (Losada y Whittingslow, 2013). La familia de la persona que sufre AN ocupa un lugar importante tanto física como psicológicamente ya que puede actuar como un 
factor protector del trastorno, apoyando a la persona, brindándole recursos para que pueda mejorar su situación, aunque también en algunos casos el entorno familiar actúa como factor mantenedor de AN en caso de ser una familia disfuncional, donde se encuentran conflictos en los vínculos y no le brindan a la persona enferma el apoyo suficiente. (Losada y Charro, 2018).

\section{REDES SOCIALES}

A lo largo de la adolescencia hay una preocupación por la imagen corporal, generalmente los varones tienen un interés por su fuerza física y a las mujeres les preocupa su aspecto físico. El problema se expresa cuando estas preocupaciones se llevan a un extremo, pudiendo causar trastornos alimentarios como Anorexia Nerviosa (Craig y Baucum, 2009). Esta etapa se caracteriza por la relevancia que adquieren los pares y la necesidad de su validación como refuerzo identitario. En la actualidad la interacción con los pares ocurre en espacios reales y en los espacios virtuales de las redes sociales, las cuales tienen como objetivo crear un lugar digital en el cual las personas puedan comunicarse, interactuar, compartir opiniones o experiencias (Echeburúa y Requesens, 2012).

Las redes sociales son una plataforma en internet que permite a las personas relacionarse, compartiendo intereses y aficiones donde cada participante crea un perfil personal, con la información que quiere dar a conocer (Sádaba y Bringué, 2011). Ofrece a sus usuarios un servicio de comunicación, en el cual cada uno de los miembros crea un perfil con sus datos personales, posibilitando la comunicación y conexión con otros usuarios (Antón, 2012). Los usuarios comparten fotos, datos, videos, contenido de todo tipo, lo cual podría llegar a ser considerado como un riesgo ya que al tener una cuenta pública cualquier usuario de distintas partes del mundo puede acceder a nuestra información publicada, disminuyendo el límite de la privacidad, como así también podría suceder una suplantación de la identidad online donde un usuario anónimo se hace pasar por otro usuario, utilizando sus fotos y su identidad online (Fernández y Peña, 2020).

Gracias al avance tecnológico, los jóvenes y la población en general tienen acceso a información de todo tipo, pero muchas páginas web no cuentan con una normativa que regule su contenido, por lo cual, los usuarios pueden encontrar un contenido tanto positivo como negativo. Si bien las redes sociales han ampliado posibilidades de comunicación y de obtención de información, también pueden ser consideradas una amenaza en caso de no utilizarlas de manera correcta sin control ni restricciones (Ramírez, 2019).

Las más populares para los adolescentes son Facebook, Instagram y YouTube, cuyo contenido se expresa en la publicación de imágenes atractivas, la mayoría con filtros, edición, y videos. El problema se presenta cuando a partir del contenido publicado, la persona comienza a recibir comentarios dañinos que repercuten negativamente en la percepción de su imagen corporal (Pérez y Cassany, 2018).

Instagram es una red social que permite la publicación de imágenes o videos en el perfil de cada usuario. También brinda la posibilidad de subir historias que permanecen visibles por 24 horas, donde los usuarios publican contenido sobre su rutina, comparten imágenes o videos de sus actividades individuales o junto a amigos los cuales pueden ser etiquetados para que otros usuarios puedan entrar a su perfil y compartir dicha información (Cristofol et al., 2018). Esta red social brinda la posibilidad de agregarle efectos, marcos, contraste o saturación a las fotografías, como así también pueden incorporar "hashtags", es decir etiquetas, con una palabra clave para que otros usuarios filtren la búsqueda con temas de interés. Una vez que son subidas puede recibir reacciones como me gusta o comentarios de otros usuarios (Segura Alarcón et al., 2017).

$\mathrm{Si}$ bien las redes sociales son herramientas favorables, también hay que tener en cuenta que repercuten en la vida social y emocional de los usuarios, por lo cual deben ser utilizadas de manera prudente, de lo contrario podría desencadenar estados de ansiedad, depresión, estrés, TCA o dificultad la manera de comunicarse de una persona. Además, el uso de redes sociales podría generar preocupación en los usuarios respecto de su imagen corporal, generando una insatisfacción con respecto a su físico, donde el ideal de belleza para la mayoría de los adolescentes, desencadenando una discordancia entre la imagen corporal que el sujeto percibe de sí mismo y la imagen 
que tiene como ideal a alcanzar (Romo del Olmo, 2020).

Se debe tener control con el contenido que se sube ya que existe la posibilidad de tener la cuenta pública, es decir, cualquier usuario de cualquier parte del mundo puede acceder a nuestro perfil y ver nuestro contenido, por lo cual, es importante tener en cuenta la opción de poner la cuenta privada, donde cada usuario decide quién puede comenzar a seguirlo y quien no, estableciendo un límite en su privacidad, a diferencia de las cuentas públicas que generalmente son de usuarios a los que les interesa lograr un alto número de seguidores ya que eso les brinda mayor popularidad en la red (Tecles, 2018).

Las redes sociales tienen su lado positivo, ya que al utilizarlas se logra estimular algunas regiones cerebrales, aumentando la memoria de trabajo y generando una mayor capacidad de aprendizaje perceptual (Fernández y Peña, 2020). Además permite el intercambio de información con otros usuarios como así también el contacto con otras personas o familiares que viven en otros destinos geográficos, por lo cual las redes les permiten escribirse o incluso hacer video llamada, lo cual les brinda la posibilidad de verse y escucharse en vivo a través de una pantalla. Es una gran herramienta para que algunos usuarios puedan superar la timidez, el aislamiento o la fobia social (Fernández y Peña, 2020). Además, el uso de Internet favorece la comunicación y es una gran herramienta en el ámbito educativo, ya que permite aprender y enseñar (Muñoz y Ramírez, 2016).

A pesar de esto, el uso excesivo o inadecuado de las redes sociales puede generar riesgos psicológicos o sociales especialmente en la adolescencia ya que es una etapa que conlleva grandes cambios (Fernández y Peña, 2020). El mundo virtual permite que se creen falsas identidades, como así también puede distanciar a las personas de su vida real ya que dejan de lado tareas importantes debido a que pasan demasiado tiempo en las redes, interfiriendo negativamente a nivel social, familiar, educativo o laboral. Además, este uso excesivo e inadecuado de las redes puede generar que las personas prefieran comunicarse mediante las redes sociales que en persona, regulando su estado de ánimo según el acceso a internet (Muñoz y Ramírez,
2016) como así también depresión, síndrome de déficit atencional con hiperactividad, disminución del rendimiento académico, insomnio, aumento de interacciones agresivas, alto grado de exposición y baja capacidad de desarrollar habilidades sociales (Arab y Díaz, 2015).

Con el incremento del uso de redes sociales, en algunas personas se observa una adicción a las redes sociales la cual se caracteriza por estar conectados a la red por varias horas seguidas, donde en un primer momento resulta placentero, pero luego es un hábito incontrolable (Escurra y Salas, 2014). Cuando estas personas no pueden utilizar las redes sociales experimentan un síndrome de abstinencia en el cual se hacen presentes sentimientos de malestar emocional tales como estado de ánimo disfórico, insomnio, irritabilidad y malestar emocional como aburrimiento, ira y soledad (Echeburúa y De Corral, 2010). Puede llegar a considerarse como una adicción psicológica ya que tiene características que se repiten en otro tipo de adicciones tales como pérdida de control, gran dependencia psicológica, pérdida de placer o interés en otras actividades, interferencia en cotidianeidad, asistencia. Lo que permite que las redes sociales se vuelvan adictivas es que pueden convertirse en sustitutas de la vida real, por lo cual, por ejemplo en casos de personas con déficits de habilidades sociales, timidez, o baja autoestima, son una gran herramienta para conectar virtualmente con otras personas. Además, las redes permiten interactuar con otros usuarios, a la vez de visualizar imágenes, sonidos y también se puede acceder a juegos en línea (Muñoz y Ramírez, 2016).

Dentro de las redes sociales, se encuentran ciertas personas denominadas influencers, las cuales crean contenido de interés para su público que se encuentra fragmentado por intereses en común y comparten información que a ese público le resulta interesante, y donde se crea un vínculo emocional al sentirse identificados, por lo cual la audiencia comienza a seguir sus pasos (Pérez y Campillo, 2016). El contenido publicado por estos modelos inspiradores suele basarse en una demostración de un estilo de vida saludable, no obstante, algunos de ellos publican contenido no saludable generando que el público compare su apariencia física con la de la persona 
de influencia (King University, 2019). Además, son líderes de opinión que tienen la capacidad de transmitir mensajes o contenido de forma rápida y eficaz, adquiriendo credibilidad ante los usuarios que lo siguen, por lo cual, su opinión es importante para ellos y siguen sus recomendaciones ya que al dar su opinión, consejos o comentar su experiencia sobre ciertos productos que ofrecen son percibidos como figuras que transmiten confianza y empatía (Izquierdo, 2019). Estos influencers buscan adaptar su lenguaje dependiendo del público que más los consuma, utilizando principalmente fotos y vídeos para exponer sus puntos de vista, brindar información, dar consejos y agradecer el apoyo de los usuarios. Además, tienen una gran cantidad de seguidores lo cual hace que el alcance que podrían tener sus opiniones o el contenido que comparte tenga mayor repercusión (Ramírez, 2019).

Los llamados haters, u odiadores son aquellos que atacan todo el contenido que no sea de su agrado, como así también son usuarios que le generan discursos de odio generando comentarios negativos, crueles, con la intención de generar un impacto en el lector. Estos usuarios logran obtener placer a través de la persecución, humillación y denigración hacia otro. No solo realizan ataques verbales ofensivos, sino que también en algunos casos estos mismos usuarios agreden físicamente a otros (Busón, 2020). Estos usuarios se dedican a criticar a otros a través de las redes sociales y están constantemente alerta al contenido que realizan los usuarios que no les agradan, para poder difamarlos o hacer comentarios negativos. Además, los haters suelen ser definidos como personas siniestras y desconfiadas ya que tienden a creer que su pensamiento o su postura es la correcta y no están abiertos al diálogo positivo que genere un intercambio de ideas, por lo contrario, les gusta llevar la contra de lo que se encuentra publicado (Tecles, 2018).

El uso excesivo de redes sociales puede desencadenar consecuencias físicas, psicológicas y sociales. Las consecuencias físicas se relacionan con el sedentarismo ya que al estar varias horas con las redes la persona deja de lado la actividad física, junto a una sensación de cansancio en el cuerpo la cual se produce por mantener la misma postura durante muchas horas, como así también se ve afectado el sueño ya que muchos suelen quedarse despiertos más de lo debido para seguir utilizando las redes. Este uso excesivo también podría desencadenar fatiga ocular ya que se pasa mucho tiempo seguido frente a pantallas electrónicas (Chimbana, 2020).

Al momento de intentar observar una adicción a las redes sociales, las principales señales de alarma que se deben tener en cuenta son la privación del sueño por usar las redes sociales, el descuido de otras actividades importantes, como por ejemplo el contacto con el entorno o la falta de cuidado personal, como así también el pensamiento constante de una necesidad de utilizar las redes sociales junto a una fuerte frustración cuando la conexión comienza a fallar o se torna lenta, o un intento de limitar el tiempo de uso y no lograrlo (Echeburúa y De Corral, 2010). Es importante tener en cuenta si el uso de redes sociales aumenta y disminuye el rendimiento académico como consecuencia de pasar todo el día en línea postergando sus actividades, también los usuarios suelen quedarse hasta tarde conectados aunque no haya otro usuario conectado para conversar. Además, se puede ver en la persona un estado de irritabilidad o de ansiedad al no estar conectado, como así también el estar pendiente a cada momento de la llegada de una notificación o creer que ha vibrado el celular cuando en realidad no es así (Arab y Díaz, 2015).

En cuanto a las consecuencias psicológicas de la adherencia a las redes sociales de modo exclusivo - con un abandono de las redes interpersonales presencialespodrían ser algunas tales como distorsión de la noción del tiempo junto a una confusión en la distinción entre el mundo real y el imaginario, ansiedad que genera la necesidad de permanecer conectado a la red, afectividad empobrecida, falta de habilidades de afrontamiento y depresión. En lo que respecta a las consecuencias psicológicas sociales puede desarrollarse un aislamiento social, bajo rendimiento académico o laboral ya que no le dedica el tiempo necesario, conflictos familiares debido a la ausencia de colaboración en tareas del hogar y cambios en la rutina diaria (Chimbana, 2020).

Se recomienda seguir una serie de pasos para llevar a cabo un buen uso de las redes sociales, tales como reconocer la dependencia, apagar las notificaciones en 
momentos importantes donde no es necesario utilizar el celular, evitar la impulsividad de compartir contenido antes de chequearlo. Se les recomienda a los padres que tienen niños pequeños o llegando a la adolescencia que establezcan un horario fijo para establecer el fin de las redes sociales cada día, por ejemplo, apagando el celular media hora antes de dormir. Sería deseable desarrollar un presupuesto de tiempo con sus hijos, donde ellos establezcan un horario considerable del tiempo que desean utilizar el celular cada día (La Nación, 2020), como así también es importante que se eduque a los niños y adolescentes sobre los riesgos asociados al uso de internet y explicarles que un mal uso podría generar consecuencias negativas, por lo cual se considera pertinente en ciertos casos revisar el historial de búsqueda. Además, en niños pequeños y adolescentes específicamente, es recomendable brindarles una explicación sobre el uso de internet y establecer límites en cuánto a qué páginas no pueden ingresar o qué al momento de jugar en línea no brinde información personal a ningún desconocido (Arab y Díaz, 2015).

\section{REDES SOCIALES Y ANOREXIA NERVIOSA}

Es posible que el uso de redes sociales en personas que tienen dificultades en cuanto a su aceptación y pertenencia, se desencadenen consecuencias negativas ya que muchas veces suelen generar una comparación social, pudiendo provocar envidia o depresión. Por lo cual, una persona que pase mucho tiempo en Facebook puede pensar que los demás tienen una mejor vida, desarrollando una baja autoestima (Clark, et al., 2018).

Es común que en las redes sociales, las personas que más busquen contenido sobre conceptos claves tales como: Anorexia, Mía, Ana, Bulimia, TCA sean adolescentes mujeres que ya se encuentran diagnosticadas y en tratamiento, o auto diagnosticadas. Generalmente suelen ser personas vulnerables que no sienten recibir mucho apoyo de sus familiares o amigos, por lo cual buscan esa contención dentro de las redes sociales, con otras personas que sepan entenderla ya que están atravesando la misma situación, motivo por el cual estos sitios se vuelven tan atractivos (Custers, 2015).
A través de los medios de comunicación, se transmiten ideales de belleza que ejercen presiones en la apariencia tanto en hombres como en mujeres, y estas conllevan a sentir insatisfacción ya que las personas constantemente comparan su cuerpo con el de otros supuestos ideales, e internalizan el pensamiento de que lo ideal es tener un cuerpo delgado. En muchos casos, esta insatisfacción corporal genera una alimentación disminuida y problemática, comportamientos inadecuados y una disminución desfavorable en el funcionamiento psicológico (Modica, 2020). En la exposición a los medios, la persona incorpora valores socioculturales hasta que se convierten en principios rectores y estos pueden causar angustia o cambios de comportamiento, promoviendo la insatisfacción con la apariencia física actual (Pedersen, et al., 2018). A través de las técnicas de modificación digital donde se eliminan centímetros de caderas, muslos y cinturas, los estándares de belleza sociales enfatizan en las mujeres la búsqueda de delgadez (Dakanalis, et al., 2017). Por lo cual, con frecuencia, hombres y mujeres editan o retocan sus fotos para quitar aquello que no les gusta, debido a la insatisfacción corporal que sienten al comparar sus cuerpos con los supuestos ideales que ven en las redes (Modica, 2020). Además, los me gusta y los comentarios también pueden llegar a generar consecuencias en el bienestar psicológico de los adolescentes especialmente, ya que influyen en el autoconcepto que tienen de sí mismos y el deseo de recibir una aprobación de sus seguidores, motivo por el cual editan o retocan las imágenes personales que suben a la red con el objetivo de publicar una supuesta imagen perfecta para agradar y mostrar un físico delgado o musculoso como sinónimo de belleza (Romo del Olmo, 2020).

Si bien los medios de comunicación generan un impacto en la insatisfacción corporal de las personas, específicamente en las redes sociales este impacto es aún mayor ya que dentro de las redes los usuarios pueden interactuar entre ellos, subir imágenes de ellos con la posibilidad de modificarlas agregando filtros o retoques, y ver fotos de otros con la misma probabilidad de edición (Saunders et al., 2020). Junto a la presión social, la exposición de cuerpos ideales pocos realistas como se ven en revistas, cine y televisión, influye en la percepción errónea del tamaño del cuerpo de las personas (Brooks, et al., 2016). 
El uso de redes sociales se considera una forma de presión o influencia de los medios que aumenta la posibilidad de que las personas constantemente comparen sus cuerpos en las redes sociales, siendo este uno de los motivos por el cual se podría desarrollar una problemática alimentación, la cual podría desencadenar en un trastorno de la conducta alimentaria (Modica, 2020).

Ana y Mia en la web son los nombres que se le otorgan a la Anorexia y a la Bulimia en la web. Esta denominación comenzó a ser popular en internet desde el año 2004 y hasta la actualidad, sigue vigente poniendo en contacto a miles de personas con trastornos de alimentación (Bermejo, et al., 2011). Las páginas Pro-Ana, es decir, pro anorexia nerviosa y ProMia en apoyo a la bulimia nerviosa, apoyan a los TCA como un estilo de vida el cual seguir, planteándola como un ideal al que aspiran llegar, rechazando los tratamientos médicos que sirvan de recuperación del trastorno. En estas páginas los usuarios se expresan, comparten opiniones y experiencias, información, trucos para bajar de peso u ocultar la enfermedad a su círculo cercano (Mandich, et al., 2012). Actualmente estas páginas han crecido exponencialmente, pudiendo ser encontradas en Instagram, Facebook, Twitter y Pinterest donde la mayoría de sus administradores o creadores son mujeres que padecen TCA en los cuales se suelen publicar imágenes de mujeres famosas extremadamente delgadas como inspiración para perder peso, intercambiando trucos o retos para poder realizar la disminución del peso (Custers, 2015). Ana y Mia son nombres femeninos que personifican los trastornos de Anorexia y Bulimia, conceptualizándolas como diosas perfectas, las cuales guían a las personas hacia una supuesta perfección, a la cual se llega a través del dolor, sacrificio y hambre. Ambas funcionan como un rechazo a la recuperación en un sentido aspiracional (Ramos Kurland, 2016).

Estas páginas son creadas generalmente por una persona o varias personas con TCA y crean contenido peligroso, ya que se comparten de manera recíproca trucos para ocultar la enfermedad a los padres, dándose ánimos para lograr pérdida de peso, y a veces, promoviendo el autocastigo. Entre las participantes se comparten dietas extremas sin fundamento científico que ponen en peligro la salud de las mismas, como así también es frecuente en estos foros encontrar la carrera de kilos, la cual consiste en campeonatos para adelgazar entre las consumidoras de la web (Lago Blanco, et al., 2019). Además en estas páginas suelen festejar entre las participantes el pasar hambre, planteando que cuanto mayor sea el tiempo sin ingerir alimento, más orgullosas se sentirían por el esfuerzo, por lo cual es frecuente encontrar en estas páginas frases tales como "pies juntos, muslos separados", las cuales siempre van acompañadas de imágenes de mujeres delgadas a las cuales se les marca la clavícula, los huesos de las caderas y las costillas exageradamente (García, 2020).

Este grupo de personas suelen autodenominarse como princesas ya que por lo general son adolescentes mujeres cuyo ideal de perfección es utilizado como justificación para mantener su enfermedad. En estas páginas se visualizan una gran cantidad de dietas sin fundamento científico, que ponen en riesgo la salud de quienes la siguen; trucos para adelgazar que intercambian, como por ejemplo formas de engañar al estómago, a la mente y a los padres; contador de las calorías que ingieren, ejercicios excesivos, ingesta sobreabundante de agua, dormir horas demás para evitar la ingesta de alimentos. Se inspiran con la participación en foros y con la observación de imágenes de modelos muy delgadas (Bermejo, et al., 2011).

Los foros Pro-Ana y Pro-Mia tienen una función de apoyo entre las personas que ingresan y son parte de ellos, donde se comparten opiniones y consejos, y donde se espera que todas las personas que participen establezcan una relación recíproca, brindándose ayuda y apoyo entre sí (Mandich., et al., 2012). Generalmente muchos de los usuarios que se encuentran involucradas en estas páginas son aquellas con baja autoestima, por lo cual se insertan en estos foros para lograr alcanzar un ideal de belleza exagerado y ser pertenecientes a un grupo de pares que se sientan de la misma manera. Es común que adolescentes con baja autoestima visiten estas páginas ya que por lo general suelen recibir comentarios negativos acerca de su físico, lo cual les genera una insatisfacción corporal que las lleva a someterse a dietas extremas para detener las burlas y llegar a alcanzar un ideal socialmente aceptado, con el objetivo de poder lograr controlar la forma de su cuerpo (García Guardiola, 2020). 
Generalmente suelen hacer grupos de WhatsApp o desde la red social en la que esté creada la cuenta ya sea Instagram o Facebook, donde intercambian mandamientos que establecen lo que se debe hacer y lo que no, como así también es común que cada usuario escriba cuál es su peso actual y cuál es el peso ideal al que está intentando llegar, sin ser juzgados socialmente ya que todas están pasando por la misma situación o muy parecida, por lo cual se brindan apoyo y contención mutua. Estos foros Pro-Ana y Pro-Mía han crecido exponencialmente en la red y se logran encontrar fácilmente, lo cual es un riesgo ya que antes cuando no existía este uso de redes sociales o no era tan conocido, era muy poca la cantidad de personas que compartían estos trucos o dietas extremas para adelgazar, por lo cual no se difundía tan rápidamente como en la actualidad (Custers, 2015).

Para las participantes del foro, Ana representa una experiencia necesaria y valiosa, y se hace referencia a ella como una entidad protectora que comprende los objetivos de cada una de las participantes del foro, en la cual predomina el mensaje del control del sí mismo para lograr la delgadez, demandando medidas tales como no ingerir alimentos o el excesivo ejercicio. Por lo tanto, las mismas participantes confirman que el apoyo mutuo entre ellas es necesario para mantener el trastorno, ya que fuera de las redes sociales no encuentran apoyo, generando en este intercambio distintos afanes, tales como el afán de incluir y de mostrar cariño, y de alentar a las otras participantes. En cuanto a Mia, la cual se refiere a la bulimia, es representativa de experiencias donde se recurre a la purgación debido a la falta de control (Mandich., et al., 2012).

Para distinguirse en las redes sociales utilizan iconos o imágenes de libélulas o mariposas, o mujeres escuálidas con coronas y diamantes, como una simbolización de la belleza de aspecto frágil. Además, dentro de los foros suelen colocar junto a su nombre, el número del peso que tienen como meta, que generalmente es del número 45 hacia abajo, como así también fuera de las redes sociales pueden distinguirse entre ellas utilizando una cinta roja como pulsera si son personas que sufren de anorexia nerviosa, o una cinta violeta si sufren de bulimia (Bermejo, et al., 2011). También suele ser frecuente que compartan signos de identificación tales como lazos blancos, pulseras rojas o negras con el objetivo de reconocerse entre ellas como pertenecientes al mismo grupo, los cuales también son un recordatorio de apoyo entre las participantes (Lago, et. al. 2019).

\section{CONCLUSIONES}

1. Se considera relevante profundizar sobre esta problemática ya que en los últimos años la anorexia nerviosa ha aumentado exponencialmente, tanto en hombres como en mujeres adolescentes, los cuales se encuentran en una etapa en la cual construyen su identidad y personalidad, siendo una de las enfermedades crónicas más frecuentes por su gravedad y por los riesgos que conlleva. Actualmente las redes sociales como Instagram, al filtrar la palabra Anorexia o Bulimia genera automáticamente un cartel el cual le pregunta al usuario si necesita ayuda y explica que las publicaciones que contienen esas palabras claves suelen fomentar comportamientos que provocan daños e incluso la muerte, por lo cual, si el lector necesitara ayuda, Instagram dice que estará ahí para ayudarlo. En caso de escoger la opción de necesitar ayuda, la aplicación te dirige a una página donde brinda tres opciones, primero, hablar con un amigo; segundo, hablar con un voluntario de una organización de ayuda y para eso, brinda la opción de visitar una página en Facebook llamada Suicidiología Argentina y en Perú a través de la línea de ayuda 113 desde un teléfono fijo o celular, permitiendo contactarse con profesionales; tercero, brinda sugerencias para ayudar a la persona a sentirse mejor tales como atenuar una crisis, cambiar de entorno y cuidarse. Si bien es una iniciativa correcta y positiva, se puede escoger la opción de no necesitar ayuda y de igual manera lograr visualizar todo el contenido que se encuentre relacionado con Anorexia o Bulimia. Por lo cual, se estima importante que todas las redes sociales generen el mismo cartel de ayuda que brinda Instagram ya que para usuarios vulnerables podría serle de gran ayuda y utilidad.

2. Se observó una asociación positiva entre el uso de redes sociales y el desarrollo de Anorexia 
Nerviosa en adolescentes, específicamente en mujeres. No obstante, también puede presentarse en hombres.

3. Como recomendación para próximas investigaciones sugiero poner el foco en cómo el uso de redes sociales influye en las personas, específicamente en adolescentes, ya que se encuentran en una etapa vulnerable de sus vidas por todos los cambios que esta conlleva. Además, es importante que los profesionales de la salud, tanto médicos como psicólogos o psiquiatras tengan conocimiento sobre los foros Pro-Ana y Pro-Mía, ya que su contenido suele ser peligroso para las personas que lo consumen debido a que se someten a retos extremos para adelgazar, sin tomar dimensión que podrían llevarlos a la muerte.

\section{REFERENCIAS}

American Psychiatric Association (2014). Diagnostic and statiscal manual of mental disorders $\left(5^{\mathrm{a}} \mathrm{ed}\right)$.

Antón, A. M. G. (2012). El fenómeno de las redes sociales y los cambios en la vigencia de los Derechos Fundamentales. Revista de Derecho de la UNED (RDUNED), (10), 209-253.

Arab, L. E., y Díaz, G. A. (2015). Impacto de las redes sociales e internet en la adolescencia: aspectos positivos y negativos. Revista Médica Clínica Las Condes, 26(1), 7-13.

Arnau Caro, G. (2016). Anorexia nerviosa en adolescentes: un problema prioritario. Trabajo de fin de grado de Enfermeria. Universitat Raovira i Virgili.

Bermejo, B. G., Saúl, L. Á., y Jenaro, C. (2011). La anorexia y la bulimia en la red: Ana y Mía dos "malas compañías" para las jóvenes de hoy. Acción psicológica. 71-83.

Busón, C. (2020). La minería de opinión para el análisis del discurso de odio en las redes sociales. Un estudio de caso sobre Paulo Freire en YouTube durante el periodo 2007-2019. Commons. Revista de Comunicación y Ciudadanía Digital, 9(1), 119-159.
Brooks, KR, Mond, JM, Stevenson, RJ \& Stephen, ID (2016). Body Image Distortion and Exposure to Extreme Body Tipes: Contigent Adaptation and Cross Adaptation for Self and Other. Frontiers in Neuroscience.

Caballo, V. E y Simón, M.A. (2013). Manual de psicología clínica infantil y del adolescente. Trastornos generales. Pirámide.

Castro, S. S., y Araya, C. S. (2020). Anorexia nerviosa en adolescentes y adultos. Revista Ciencia y Salud Integrando conocimientos, 4(4), 212-226.

Celis, A. y Roca, E. (2011). Terapia cognitivo conductual para los trastornos de la conducta alimentaria según la visión transdiagnóstica. Revista de Accion Psicológica, 8 (1). p. 21-33.

Clark, J. L.,Algoe, S. B., \& Green, M. C. (2018). Social network sites and well-being: the role of social connection. Current Directions in Psychological Science, 27(1), 32-37.

Chimbana Villa, J. E. (2020). Adicción a las redes sociales y su influencia en el aislamiento social en adolescentes. Tesis de grado Psicología Clínica. Universidad Técnica de Ambato.

Craig, G., y Baucum, D. (2009). Adolescencia: Desarrollo físico y cognitivo, Desarrollo Psicológico. Pearson.

Cristofol Rodríguez, C., Alcalá Vidal, A., \& Fernández Pérez, L. (2018). Análisis comparativo de las aplicaciones Snapchat e Instagram: nuevas tendencias derivadas de su uso. Redmarka: revista académica de marketing aplicado, 20, 39-76.

Custers, K. (2015). The urgent matter of online proeating disorder content and children: clinical practice. European journal of pediatrics, 174(4), 429-433.

Dakanalis, A., Clerici, M., Bartoli, F., Caslini, M., Crocamo, C., Riva, G., \& Carra, G. (2017). Risk and maintenance factors for young women's DSM-5 eating disorders. Archives of women's mental health, 20(6), 721-731.

Echeburúa, E., y De Corral, P. (2010). Adicción a las nuevas tecnologías ya las redes sociales en jóvenes: un nuevo reto. Adicciones, 22(2), 91-96. 
Echeburúa, E y Requesens, A. (2012). Adicción a las redes sociales y nuevas tecnologías en niños $y$ adolescentes. Pirámide.

Escurra Mayaute, M., y Salas Blas, E. (2014). Construcción y validación del cuestionario de adicción a redes sociales (ARS). Liberabit, 20(1), 73-91.

Escursell, R. M. R. (2017). Anorexia, bulimia y otros trastornos alimentarios. Pirámide.

Fernández, M. N. V., y Peña, R. H. (2020). Percepción y uso de las redes sociales por adolescentes. Revista de SEAPA. 2020 Mayo; 8(1), 18-30.

Fragale, K. A. (2010). Anorexia: "un llamado del Amor". Trabajo integrador, Universidad Argentina John F. Kennedy.

García Guardiola, I. (2020). Trastornos de la conducta alimentaria. Trabajo de fin de grado de Psicología. Universidad Pontificia Comillas.

Izquierdo Dones, S. (2019). Descripción del fenómeno influencer. Trabajo de fin de grado. Comillas Universidad Pontificia.

King University (2009). The Link Between Social Media and Body Image. Estados Unidos.

La Nación. (2020). El dilema de las redes sociales. Qué recomiendan los expertos en tecnología para un "uso menos tóxico".

Lago Blanco, E., Carrera Bermúdez, C., y Seijas, R. (2019). Influencia de las páginas pro-anorexia y pro-bulimia en un grupo de pacientes con trastornos de la conducta alimentaria. Trastornos de la Conducta Alimentaria, 16, 1775-1793.

Losada, A. V. y Charro, A. (2018). Trastornos de la conducta alimentaria y estilos parentales. Perspectivas metodológicas, 18(21), 89-112.

Losada, A. V y. Donovan, C. (2017). Terapia cognitiva y terapia familiar en anorexia nerviosa y bulimia nerviosa. Alternativas cubanas en Psicología, 15, 68-87.

Losada, A. V. y Marmo, J. (2013). Herramientas de Evaluación en Trastornos de La Conducta Alimentaria. Académica Española.

Losada, A. V. y Whittingslow. (2013). Familia y trastornos de la conducta alimentaria. Revista Borromeo, 4. 393-424.

Mandich, C. C., Villalobos, C. P., Bugmann, M. D., Lobos, R. C., Lackington, J. P. G., Acevedo, R. A., y Bolados, G. C. (2012). Función social de foros de internet en castellano pro-anorexia y probulimia. Revista Argentina de Clínica Psicológica, 21(2), 139-148.

Marengo, D., Longobardi, C., Fabris, MA \& Settanni, M. (2018). Highly-visual social media and internalizing symptoms in adolescence: The mediating role of body image concerns. Computers in Human Behavior, 82, 63-69.

Meler, M. E. L., y Planell, L. S. (2013). Comprender la anorexia, la bulimia y el trastorno por atracón. AMAT.

Modica, C. A. (2020). The associations between Instagram use, selfie activities, appearance comparison, and body dissatisfaction in adult men. Cyberpsychology, Behavior, and Social Networking, 23(2), 90-99.

Muñoz, N. E. y Ramírez, S. (2016). Adicción a las redes sociales y personalidad, en adolescentes. PsicoEducativa: reflexiones y propuestas, 2(4), 46-52.

Organización Mundial de la Salud (2020). Desarrollo en la adolescencia. https://www.who.int/ maternal_child_adolescent/topics/adolescence/ dev/es/

Pedersen, L., Hicks, R. E., \& Rosenrauch, S. (2018). Sociocultural pressure as a mediator of eating disorder symptoms in a non-clinical Australian sample. Cogent Psychology, 5(1).

Pérez, M. y Campillo, C. (2016). Influencer engagement, una estrategia de comunicación que conecta con la generación millenial. Trabajo de Grado en Publicidad y Relaciones Públicas. Universidad de Alicante.

Pérez Sinusía, M. y Cassany Comas, D. (2018). Escribir y compartir: Prácticas escritas e identidad en los adolescentes en Instagram. Aula de Encuentro, 20 (2). https://doi.org/10.17561/ae.v20i2.5

Portela de Santana M.L., Da Costa Ribeiro Junior H., Mora Giral M. y Raich R.M. (2012). La 
epidemiología y los factores de riesgo de los trastornos alimentarios en la adolescencia; una revisión. Nutrición Hospitalaria, 27, 391-401.

Ramírez Ríos, S. C. (2019). Incremento de anorexia en adolescentes de 15 a 19 años de edad pertenecientes al sector socio económico $\mathrm{AB}$ de Lima Metropolitana, como consecuencia del fenómeno influencer en Instagram. Tesis de Licenciatura en Arte y Diseño Empresarial. Universidad San Ignacio de Loyola

Ramos Kurland, V. (2016). La comunidad pro Ana y su influencia sobre los Trastornos de la Conducta Alimentaria. Trabajo de Fin de Grado en Psicología. Universidad de Cádiz.

Rodgers, R. F., O’Flynn, J.L., \& McLean, S.A. (2019). Media and eating disorders. The International Encyclopedia of Media Literacy, 1-10.

Romo del Olmo, M. (2020). Influencia de las redes sociales en la satisfacción de la imagen corporal de las adolescentes. Un proyecto de prevención. Trabajo de Grado en Psicología. Universidad de Cádiz

Fecha de recepción: 29 de marzo 2021

Fecha de aceptación: 4 de mayo 2021
Sádaba, C. y Bringué, X. (2011). Redes sociales. Manual de supervivencia para padres. Viceversa.

Segura Alarcón, J. G., Anguita, M. y Palma Ormeño, I. (2017). Construcción de la identidad social a través del uso de Instagram. Tesis de grado. Facultad de Educación y Humanidades Universidad del BíoBío.

Serra, M. (2015). Los trastornos de la conducta alimentaria. Los trastornos de la conducta alimentaria. UOC.

Tecles Llopis, L. (2018). Los haters en Instagram: análisis de los comentarios a influencers en España. Trabajo de fin de grado. Universidad Politécnica de Valencia.

Véliz Sánchez, M.,Aguiar Mota, C., \& Infante Aguirre, M. G. (2019). Anorexia nerviosa: trastorno poco frecuente en adolescentes varones. Medicentro Electrónica, 23(1), 64-68. 